\title{
Strategi Relational Benefit Terhadap Peningkatan Kepuasan Pelanggan Pada Alvira Mart Tikung Lamongan
}

\author{
Nurul Badriyah, Siswanto, Ishaq \\ Program Studi Magister Manajemen, Universitas Islam Lamongan \\ Email authors: nurulbadriyah@unisla.ac.id, siswanto22@gmail.com, ishaq@gmail.com
}

\begin{abstract}
ABSTRAK
Persaingan yang begitu ketat sekarang ini membuat perusahaan-perusahaan harus mampu memainkan strategi pemasaran yang handal dan mampu menarik minat konsumen. Tujuan dari penelitian ini adalah untuk mengetahui apakah confidence benefits, social benefits, special treatment benefits mempengaruhi secara parsial maupun simultan terhadap kepuasan pelanggan alvira mart. Sampel dalam penelitian ini sebanyak 75 responden. Selanjutnya dilakukan analisis data kuantitatif uji validitas, uji reliabilitas, regresi berganda, korelasi product pearson moment, uji t, dan uji F dengan hasil tiap variabel dinyatakan valid dan reliable. Dari hasil uji t diperoleh confidance benefit berpengaruh positif dan signifikan terhadap kepuasan pelanggan pada Alvira Mart Tikung Lamongan, social Benefit dan special treatment benefit tidak ada pengaruh secara signifikan terhadap kepuasan pelanggan pada Alvira Mart Tikung Lamongan. Dari hasil uji simultan variabel bebas mempunyai pengaruh yang signifikan terhadap kepuasan pelanggan pada Alvira Mart Tikung Lamongan. Dari uji regresi linier berganda dan hasil uji t menunjukkan bahwa variabel yang paling dominan mempengaruhi peningkatan kepuasan pelanggan pada Alvira Mart Tikung Lamongan adalah confidance benefit.
\end{abstract}

Kata Kunci : Confidance Benefit, Social Benefit, Special Treatment dan Kepuasan Pelanggan

\section{PENDAHULUAN}

Perkembangan dunia usaha semakin pesat, dan seiring dengan pesatnya perkembangan tersebut berbagai permasalahan bermunculan, sehingga banyak kendala dan permasalahan yang harus di hadapi perusahaan. Dalam dunia usaha dengan perkembangannya dituntut dengan banyak kegiatan yang semakin komplek, dan dalam mencapai tujuannya banyak cara yang ditempuh oleh perusahaan agar produk yang dihasilkan dikenal konsumen atau masyarakat sehingga menimbulkan keinginan untuk membeli hasil produksinya. Kegagalan pada manajeman perusahaan dalam mencapai tujuannya disebabkan keputusan manajeman yang kurang sehat, karena didasarkan pada informasi yang kurang tepat. Dalam mengelola dan menjalankan perusahaan, manajeman perusahaan sangat membutuhkan informasi-informasi yang dapat membantu dalam proses pengambilan keputusan pembelian dan strategi perusahaan dalam menghadapi pesaingnya.

Melakukan usaha baik barang atau jasa harus memiliki teknik manajeman pemasaran. Hal ini bertujuan untuk mengenal dan memahami pelanggan sedemikian rupa dan produk yang di jual akan cocok sesuai dengan keinginan pelanggan, sehingga produk tersebut dapat terjual dengan sendirinya. Beberapa strategi pemasaran diantaranya adalah Relational Benefit atau manfaat hubungan. Relational benefit adalah hal yang akan dirasakan oleh pelanggan ketika telah menerima layanan dari perusahaan penyedia jasa yang memiliki nilai yang lebih tinggi dibandingkan apa yang mereka harapkan/dapatkan dari perusahaan lainnya. Ketika perusahaan mampu dengan konsisten menyampaikan nilai dari sudut pandang pelanggan, maka satu manfaat (benefit) akan dirasakan pelanggan dengan lebih jelas yang akan mendorong mereka untuk mempertahankan hubungan. Relational benefit terdiri atas confidence benefits, social benefits, dan special treatment benefits (Maria-Eugenia et al.,2009).

Beberapa pendekatan dapat digunakan dalam memberikan manfaat atas suatu hubungan atau relational benefits, namun yang umumnya digunakan adalah confidence benefits, social benefits dan special treatment benefits (Molina et al., 2009; Dimitriadis, 2010; Kinnar dan Capella, 2006; Molina et al., 2007). Confidence benefits merupakan salah satu manfaat hubungan 
berupa kepercayaan yang terjalin oleh perusahaan maupun pelanggan. Pelanggan akan merasa aman, ketika dilayani oleh perusahaan yang telah dipercaya, dan perusahaan akan lebih nyaman dalam memberikan pelayanan ketika telah mendapatkan kepercayaan dari pelangggan. Social benefits merupakan bentuk manfaat dari sebuah hubungan berupa keakraban yang terjalin oleh pelanggan dan perusahaan. Manfaat sosial akan membuat pelanggan lebih nyaman dalam menyampaikan keluhan serta masalah yang telah dihadapi, dan perusahaan akan mampu lebih akurat dalam memecahkan masalah yang dihadapi oleh pelanggan. Special treatment benefits merupakan bentuk manfaat berupa perlakuan istimewa yang diterima oleh pelanggan. Manfaat perlakuan istimewa diharapkan dapat membuat konsumen merasa lebih dihargai dan akhirnya menjadi loyal kepada perusahaan.

Pelanggan yang merasa mendapatkan nilai atau manfaat (relational benefit) dari program relationship marketing, akan merasakan suatu kepuasan. Kotler (2006) mengemukakan bahwa kepuasan pelanggan adalah tingkat perasaan seseorang setelah membandingkan antara kinerja yang dirasakan dengan harapannya. Pelanggan mengalami berbagai tingkat kepuasan dan ketidakpuasan, setelah mengalami atau merasakan masing-masing jasa sesuai dengan sejauh mana harapan mereka terpenuhi atau terlampaui (Ndubisi \& Chan, 2005; Kim, 2005).

Berdasarkan hasil ulasan di atas maka tujuan dari penelitian ini adalah untuk menganalisis dan membahas pengaruh confidence benefits, social benefits, special treatment benefits terhadap kepuasan pelanggan Alvira Mart Tikung Lamongan baik secara parsial maupun simultan.

\section{METODE PENELITIAN}

Penelitian ini dilakukan selama 4 bulan dari bulan November 2018 sampai dengan bulan Maret 2019. Penelitian ini dilakukan di Alvira Mart Tikung Lamongan. Jenis penelitian dalam penelitian penulis merupakan penelitian diskriptif kuantitatif, yang menurut Sugiyono (2014) adalah "Sebuah penelitian yang datanya menggunakan angka-angka dan analisis menggunakan statistik". Populasi dalam penelitian ini adalah konsumen yang melakukan pembelian selama 3 bulan di Alvira Mart Kecamatan Tikung Kabupaten Lamongan selama penelitian dilakukan sejumlah 300 orang. Karena keterbatasan waktu, biaya dan tempat, maka peneliti dapat menggunakan sampel sebanyak 75 responden yang diambil dari populasi tersebut. Sampel dalam penelitian ini dapat diketahui dengan cara menggunakan rumus Solvin. Jenis Data yang digunakan adalah Data sekunder adalah data pelengkap yang diperoleh dari instansi terkait, berupa buku-buku acuan dan dokumentasi.

Dalam penulisan ini, metode pengumpulan data yang penulis tempuh adalah Metode Kuisioner (angket), Metode Observasi, Metode Wawancara. Variabel independent (X) dalam penelitian ini adalah Confidance Benefit dengan indikator (1) dapat dipercaya (2)dapat diandalkan (3) layanan sesuai janji, Social Benefit dengan indikator (1) Perlakuan personal yang baik (2) Hubungan pertemanan (3) Keakraban dengan karyawan dan Special Treatment Benefit dengan indikator (1) Potongan harga (2) Harga yang berbeda (3) Layanan yang berbeda. Variabel dependent (Y) dalam penelitian ini adalah kepuasan pelanggan dengan indikator (1) Puas dengan produk (2) Puas dengan perlakuan perusahaan (3) Puas dengan keseluruhan produk (Muhammad Yaskun:2017).

Metode yang digunakan dalam penelitian ini adalah menggunakan metode kuantitatif dari data yang berupa angka-angka dihitung menggunakan perhitungan rumus statistik sebagai berikut : (1) Uji Validitas (2) Uji Realibilitas (3) Uji Korelasi Product Moment (4) Uji Analisis Regresi Berganda (5) Uji F atau Uji Simultan (6) Uji t atau Uji Parsial

\section{TEMUANDAN PEMBAHASAN}


Dalam penelitian ini penulis menetapkan bahwa variabel yang mempengaruhi adalah variabel bebas yaitu confidance benefit X1, social benefit X2, special treatment benefit X3 dan variabel terikat yaitu kepuasan pelanggan (Y). Hipotesa adalah dugaan sementara yang perlu dibuktikan kebenarannya, maka dari itu perlu diadakan hipotesa agar dapat diketahui sampai mana kebenaran hipotesa tersebut. Pengolahan data dilakukan dengan bantuan software SPSS 20. Hasil analisis uji validitas digunakan untuk menguji sejauh mana ketepatan alat pengukur dapat mengungkapkan konsep gejala atau kejadian yang diukur. Diketahui bahwa semua indikator untuk variabel Confidance Benefit (X1), Social Benefit (X2), Special Treatment Benefit (X3), dan Kepuasan pelanggan (Y) mempunyai nilai korelasi diatas $\mathrm{R}$ tabel dengan $\mathrm{R}$ tabel 0,227 . Hal tersebut menunjukkan bahwa semua indikator dari masing-masing variabel bisa dikatakan valid, atau dapat mengukur variabel - variabel tersebut dengan tepat. Uji Realibilitas dengan membandingkan milai Alpha Cronbach's diperoleh koefisien alpha Confidance Benefit sebesar 0,831, Social Benefit sebesar 0,831, Special Treatment Benefit sebesar 0,833 dan kepuasan pelanggan sebesar 0,842 . Pada taraf $a=0,05$ dan $n=75$ diperoleh ternyata koefisien alpha yang diperoleh masing-masing variabel adalah $>0,6$ yang artinya instrument yang digunakan Reliabel. Dari hasil uji korelasi product moment pearson dengan pengolahan data dengan menggunakan SPSS 20 hasil analisis korelasi product moment pearson menunjukkan bahwa hubungan antara variabel terikat (Y) yaitu kepuasan pelanggan Alvira Mart Tikung Lamongan dengan variabel bebas (X) yaitu Confidance Benefit (X1) adalah 0,686 yang berarti mempunyai hubungan yang sedang, Social Benefit (X2) adalah 0,408 yang berarti mempunyai hubungan yang lemah, Special Treatment Benefit (X3) adalah 0,139 yang berarti mempunyai hubungan yang sangat lemah.

Hasil dari analisis regresi linear berganda yaitu sebagai berikut:

Tabel 1. Hasil Analisis Regresi Linear Berganda

\begin{tabular}{llc}
\hline \multicolumn{1}{c}{ Keterangan } & \multicolumn{1}{c}{ Nilai } & \multicolumn{1}{c}{ Sig. } \\
Konstanta (a) & 0,821 & 0,624 \\
Koefisien Regresi $\left(b_{1}\right)$ & 0,770 & \\
Koefisien Regresi $\left(b_{2}\right)$ & 0,266 & \\
Koefisien Regresi $\left(b_{3}\right)$ & $-0,162$ & \\
$t_{\text {hitung1 }}$ & 7,123 & 0,000 \\
$t_{\text {hitung2 }}$ & 2,249 & 0,028 \\
$t_{\text {hitung3 }}$ & $-1,398$ & 0,166 \\
$F_{\text {hitung }}$ & 25,335 & \\
R Square & 0,517 & \\
\hline
\end{tabular}

Sumber: Output SPSS

Dari tabel 1 di atas, dihasilkan persamaan regresi linier berganda sebagai berikut:

$$
\mathrm{Y}=0,821+0,770 \times 1+0,266 \times 2-0,162 \times 3
$$

Keterangan:

$\mathrm{Y}=$ Kepuasan Pelanggan

$\mathrm{X} 1=$ Confidance Benefit

$\mathrm{X} 2=$ Social Benefit

$\mathrm{X} 3$ = Special Treatment Benefit

Berdasarkan tabel 1 di atas dapat dilihat nilai $t_{\text {hitung }}$ variabel Confidance Benefit $\left(X_{1}\right)$ sebesar 7,123 dengan nilai probabilitas signifikan yaitu $0,000<0,05$. Dapat dikatakan bahwa Confidance Benefit berpengaruh secara parsial terhadap minat beli konsumen. Sedangkan untuk variabel Social Benefit $\left(X_{2}\right)$ nilai $t_{\text {hitung }}$ sebesar 2,249 dengan nilai probabilitasnya sebesar 0,028 $<0,05$ jika ditinjau dari nilai $t$ hitung dan $t$ tabel diperoleh bahwa Dari hasil uji $t$ diperoleh $t$ 
hitung variabel confidance benefit (X1) 7,123 > 2,290 maka H0 ditolak dan H1 diterima. Hal ini berarti variabel Confidance Benefit (X1) berpengaruh positif dan signifikan terhadap kepuasan pelanggan (Y). sedangkan t hitung variabel social benefit X2 2,249<2,290, special treatment benfit X3 -1,398 <2,290 maka H0 diterima dan H1 ditolak. Hal ini berarti variabel Social Benefit (X2), special treatment benefit (X3) berpengaruh negatif dan tidak signifikan terhadap kepuasan pelanggan (Y).

Dari hasil uji $\mathrm{F}$ dapat dilihat hasil pengujian berdasarkan uji ANOVA atau uji statistik $\mathrm{F}$ bahwa $\mathrm{F}$ hitung $=25,335$ dengan signifikansi ( $\mathrm{Sig}$ ) sebesar 0,000. Nilai signifikansi ini menyakinkan bahwa pada model regresi yang dihasilkan terdapat pengaruh yang signifikan. Dapat juga dibandingkan dengan $F$ tabel. Pada taraf nilai signifikan $\alpha=0,05$ dengan $\mathrm{df}=\mathrm{n}-\mathrm{p}-1$ $(75-3-1=71)$ maka nilai $F$ tabel $=2,73$. Artinya $F$ hitung $(25,335)>F$ tabel $(2,73)$. Dengan melihat hasil uji $\mathrm{F}$ ini, maka diperoleh asumsi bahwa $\mathrm{H} 0$ ditolak dan $\mathrm{H} 1$ diterima, sehingga terdapat pengaruh yang signifikan antara variabel Confidance Benefit (X1), Social Benefit (X2) dan Special Treatment Benefit (X3) terhadap kepuasan pelanggan (Y) pada Alvira Mart Tikung Lamongan.

Berdasarkan tabel juga dapat didefiniskan bahwan nilai a $=0,821$ artinya nilai konstanta yang menyatakan apabila Confidance Benefit, Social Benefit, Special Treatment Benefit dianggap konstan $(\mathrm{X} 1, \mathrm{X} 2$, dan $\mathrm{X} 3=0)$ maka kepuasan pelanggan akan naik atau bertambah sebesar 0,821. b1=0,770, artinya jika Confidance Benefit atau Manfaat Kepercayaan (X1) dinaikkan satu satuan, maka kepuasan pelanggan akan naik atau bertambah sebesar 0,770 dengan asumsi variabel lain yang mempengaruhi dianggap konstan ( $a, X 2$ dan X3 =0). b2 =0,266, artinya jika Social Benefit atau Manfaat Sosial (X2) dinaikkan satu satuan, maka kepuasan pelanggan akan naik atau bertambah sebesar 0,266 dengan asumsi variabel lain yang mempengaruhi dianggap konstan $(\mathrm{a}, \mathrm{X} 1 \mathrm{dan} \mathrm{X} 3=0) . \mathrm{b} 3=-0,162$, artinya jika Special Treatment Benefit atau Manfaat Perlakuan Khusus (X3) dinaikkan satu satuan, maka kepuasan pelanggan akan mengalami penurunan sebesar 0,162 dengan asumsi variabel lain yang mempengaruhi dianggap konstan (a, X1 dan X2 = 0)

Dari hasil analisis ini juga diketahui bahwa variabel Confidance Benefit (X1) berpengaruh paling dominan terhadap kepuasan pelanggan (Y) pada Alvira Mart Tikung Lamongan. Hal ini dibuktikan dengan nilai Beta dari variabel Confidance Benefit (X1) sebesar 0,770 atau 77,0\% yang merupakan Beta lebih besar dibandingkan dengan Beta variabel Social Benefit (X2) sebesar 0,266 atau 26,6\% dan variabel Special Treatment Benefit (X3) sebesar -0,162 atau -16,2\%. Hasil nilai koefisien determinasi $\left(R^{2}\right)$ sebesar 0,517 , artinya confidence benefits, social benefits dan special treatment benefits berkontribusi mempengaruhi Kepuasan pelanggan sebesar 51,7\% sedangkan sisanya sebesar 48,3\% dipengaruhi oleh variabel lain di luar variabel yang diteliti oleh peneliti.

\section{KESIMPULAN DAN SARAN}

Berdasarkan pembahasan dari hasil analisis dapat disimpulkan bahwa variabel confidence benefits, social benefits dan special treatment benefits secara simultan berpengaruh positif dan signifikan terhadap kepuasan pelanggan. Dari hasil uji t (parsial) diperoleh nilai t hitung Confidance Benefit $(7,123)$, > t tabel 2,290. Dengan nilai signifikasi kurang dari 0,05. Hal ini berarti variabel bebas mempunyai pengaruh yang signifikan dalam mempengaruhi kepuasan pelanggan pada Alvira Mart Tikung Lamongan. Sedangkan pada Social Benefit $(2,249)$, Special Treatment Benefit $(-1,398)<\mathrm{t}$ tabel 2,290 yang berarti tidak ada pengaruh secara signifikan terhadap kepuasan pelanggan pada Alvira Mart Tikung Lamongan. Secara simultan variabel bebas ( Confidance Benefit, Social Benefit, dan Special Treatment Benefit) mempunyai pengaruh yang signifikan terhadap kepuasan pelanggan pada Alvira Mart Tikung Lamongan.. Hal ini bisa dibuktikan dengan nilai $\mathrm{F}$ hitung sebesar 25,335 > F tabel 2,73 dengan tingkat 
signifikan kurang dari 0,05 yaitu sebesar 0,000.Dari uji regresi linier berganda didapatkan suatu persamaan regresi $\mathrm{Y}=0,821+0,770 \mathrm{X} 1+0,266 \mathrm{X} 2-0,162 \mathrm{X} 3$

Dari perhitungan dengan menggunakan analisis regresi linier berganda diatas, maka dapat diketahui variabel Confidance Benefit yang berpengaruh paling dominan terhadap kepuasan pelanggan pada Alvira Mart Tikung Lamongan karena pelayanan $(\mathrm{X} 1)=0,770$ sedangkan fasilitas $(X 2)=0,266$, dan tarif $(X 3)=-0,162$. Serta nilai uji thitung nilai pelayanan $(X 1)=7,123$ sedangkan fasilitas $(\mathrm{X} 2)=2,249$, dan tarif $(\mathrm{X} 3)=-1,398$

Setelah mengetahui hasil analisis tersebut diatas, masalah yang sedang dihadapi beserta penyebabnya, maka pada kesempatan ini penulis akan kemukakan saran-saran yang mungkin bermanfaat atau setidaknya dapat dijadikan pertimbangan pada Alvira Mart dalam rangka mencapai tujuan yang telah direncanakan. Dengan adanya penelitan ini, kiranya dapat memberikan suatu masukan atau motivasi kepada Alvira Mart Tikung Lamongan dalam proses pemasarannya agar produk barang yang di jual bisa mencapai target yang direncanakan. Alvira Mart Tikung Lamongan sudah dianggap baik oleh para konsumen, tetapi ada baiknya apabila penataan tempat bisa lebih nyaman lagi. Bagi penelitian selanjutnya, penulis berharap objek penelitian dapat lebih diperbesar ke minimarket yang ada di kabupaten Lamongan. Tujuannya adalah agar hasil penelitian dapat lebih variatif dan peneliti dapat mengetahui serta membandingkan kendala yang muncul dan dihadapi.

\section{DAFTAR PUSTAKA}

Dimitriadis, Sergios. 2010. Testing Perceived Relational Benefits As Satisfaction And Behavioral Outcomes Drivers. International Journal of Bank Marketing, Vol. 28, No. 4, pp. 297-313.

Kotler, 2006. Manajemen Pemasaran Edisi ke Sebelas, Jilid II. Jakarta: Indeks Kelompok Gramedia.

Molina, Maria Eugenia, Irene Gil-Saura, and Gloria Berenguer Contri. 2009. Relational Benefits And Loyalty in Retailing: An Inter Sector Comparison. International Journal of Retail \& Distribution Management, Vol. 37 No. 6, pp. 493-509.

Ndubisi, Nelson Oly, and Chan Kok Wah. 2005. Factorical and Discriminant Analyses of Underpinnings of Relationship Marketing and Customer Satisfaction. International Journal of Bank Marketing, Vol. 23 No. 7, pp. 542-557.

Sugiyono. 2014. Metode Peneitian Kuantitatif, Kualitatif, dan R\&D. Cetakan Kedua puluh. Bandung: CV. Alfabeta.

Thurau, Thorsten, Kevin P. Gwinner, Dwayne D. Gremler. 2002. Understanding Relationship Marketing Outcomes: An Integration of Relational Benefits and Relationship Quality. Journal of Service Research, Vol. 4, No. 3.

Yaskun,Mohammad.2017. Peranan Relational Benefits Peningkatan Kepuasan Dan Loyalitas Pelanggan Mebel Lamongan .Jurnal Studi Manajemen dan Bisnis.Volume 4 No. 2.

Zheithaml, Valerie A., Mary Jo Bitner, and Dwyne D. Gremler. 2006. Service MarketingIntegrating Customer Focus Across The Firm. 4th Edition. New York: McGraw Hill. 